\title{
Efficiency of letrozole loaded PLGA nanoparticles on sex reversal of Poecilia reticulata (Peters, 1859)
}

\author{
Harshavardhan D. Joshi ${ }^{*}$, Gajanan S. Ghode ${ }^{2}$ and Sandeep B. Gore ${ }^{3}$ \\ ${ }^{1}$ Aquaculture Division, Central Institute of Fisheries Education, Andheri (West), Mumbai-400061, INDIA \\ ${ }^{2}$ Aquatic Environment and Health Management Division, Central Institute of Fisheries Education, Andheri (West), \\ Mumbai-400061, INDIA \\ ${ }^{3}$ Department of Fisheries Engineering, College of Fishery Science, Nagpur- 440001, INDIA \\ *Corresponding author. E-mail: harshjoshicofsn@gmail.com
}

Received: August 14, 2014; Revised received: April 15, 2015; Accepted: May 16, 2015

\begin{abstract}
Males of Poecilia reticulata showed extreme diversity in color, particularly of their fins, while the females lack the bright colors and are largely whitish. Such extreme variability of color and finnage lead to demand of males in the markets. The aim of present work was to develop a new Letrozole (LTZ)-loaded PLGA nanoparticles for effective delivery of the masculinization drug, letrozole, as an alternative to commercially available masculinization agents. The LTZ-loaded PLGA NPs were prepared by solvent displacement technique. The particle size of LTZ-loaded PLGA NPs was analyzed using LICOMP particle size analyzer and was found to be in the range of 72 $\mathrm{nm}$ to $520 \mathrm{~nm}$ with average size of $221.5 \pm 63.3 \mathrm{~nm}$. Zeta potential was estimated to be about $21.35 \mathrm{mV}$ with loading efficiency of $43.63 \pm 4.63 \%$. In the present study, a series of experiments were carried out to induce masculinization using LTZ-loaded PLGA nanoparticles during the sex differentiation period. Guppy ( $P$. reticulate) fry were treated with LTZ-loaded PLGA nanoparticles at dosages 5, 25, 50 and 100 ppm/kg diet for 10, 15 and 30 days. The gonopodium index and GSI showed increasing order in male and female respectively with dose of LTZ-loaded nanoparticles. The results indicated an increase in the proportion of males with dosage and duration of treatment. This has been done for the first time using nanotechnology efficiently which has shown an increase in the male population of Poecilia reticulata with lesser dose of nano-encapsulated Letrozole (LTZ)-loaded PLGA nanoparticles drug as compared with naked control Letrozole (LTZ) drug delivery.
\end{abstract}

Keywords:, Letrozole, Masculinization Nanoparticle PLGA, Poecilia reticulata

\section{INTRODUCTION}

Among aquarium fishes, guppy (Poecilia reticulata) is probably the most popular next to goldfish. It was originally called "the millions fish" because of its widespread distribution from the Caribbean islands of St. Lucia, Barbados and Trinidad to northern part of South America. Another name used is rainbow fish, because the male is colorful in patches of red, orange, yellow, green, and violet, with a few black spots. Males are extremely variable in color, while the females lack the bright colors and are largely whitish. Such extreme variability of color and finnage enthused aquarists to develop many beautiful strains as seen today (Hallgren et al., 2006).

The process of aromatization and activation of aromatase enzyme complex that leads to yield of estrone and estradiol from androgen precursors and also inhibition mechanism of aromatase enzyme complex is described by Pasmanik and Callard (1988) and Brodie (1991). There are two types of aromatase inhibitors viz, natural and synthetic. Androstenedione and testosterone are natural inhibitors, whereas Fadrozole, Letrozole,
Anastrozole and Aminoglutethimide are the synthetic inhibitors. Natural aromatase inhibitors act by hydroxylation which gives rise to an unbreakable covalent bond thus permanently blocking off aromatase enzyme complex, while synthetic inhibitors reversibly bind to the enzymes active site. Letrozole, as described is a synthetic drug and has affinity for the group of aromatase enzyme. This makes letrozole a selective and potent inhibitor (Brodie, 1991).

Although in fish, as in other animals, sex is genetically determined; in many cases it has been possible to manipulate the sex through hormone administration. If the fry are fed a diet containing sex steroids before natural sex differentiation takes place, they will develop as males or as females, depending on the hormone used. The application of androgen or estrogen to the developing embryo or juvenile fish overrides the endogenous sex determining mechanism and directs it in a male or female direction or induces sterility by completely inhibiting gonadal development. However, use of such hormones is always associated with certain controversies such as induction of sterility and residual effects on the organism (Hallgren et al., 2006). To avoid such 
controversies, it is always desirable to use these hormonal preparations in minimum dose. But to get the desired effect of these drugs, it is necessary either to increase the dose of the drug or develop a method of delivery which will give desired effect at minimum dose of it. Nanotechnology based delivery system can be used to get the result using minimum dose of the drug.

Nanoparticles (NPs) are believed to be the best drug delivery system, have substantial potential for drug targeting and exhibit several advantages over conventional delivery systems (Hughes, 2005). Since the application of nanoparticle is always associated with the concern of its ill effect, biodegradable polymeric nanoparticles have recently been the choice of the researchers. These polymers have already been used as carriers for anticancer agents (Brigger et al., 2002; Vauthier et al., 2003). With this background, the present research work was designed to develop nanoparticles of PLGA loaded with Letrozole feed for producing all male population of $P$. reticulate.

The aim of present work was to develop a new Letrozole (LTZ)-loaded PLGA nanoparticles for effective delivery of the masculinization drug, letrozole (non-steroid) as an alternative to commercially available masculinization agents, which are steroids.

\section{MATERIALS AND METHODS}

Chemicals used: Poly(D,L-lactide- $c o-$ glycolide) lactide: glycolide (50:50), mol wt 30,000-60,000, Fadrozole hydrochloride (4-(5,6,7,8-Tetrahydroimidazo[1,5-a]pyridin-5 -yl)-benzonitrile) $\geq 98 \%$ (HPLC) and Poloxamer 188 (Kolliphor $^{\circledR}$ P 188 , Poly(ethylene glycol)-block- poly (propylene glycol)-block-poly(ethylene glycol) were purchased from Sigma Chemical Co. (USA). All other chemicals and solvents were of analytical grade and purchased from Merck India. Letrozole (Sigma Chemical Co. (USA), molecular formula $\left(\mathrm{C}_{17} \mathrm{H}_{11} \mathrm{~N}_{5}\right)$ and chemical name 4,4'-(1H-1,2,4 -Triazol-1-ylmethylene) bisbenzonitrile was procured from local dealer.

Preparation of LTZ-loaded PLGA NPs: The PLGA nanoparticles and the nanoparticles loaded with Letrozole were prepared by solvent displacement technique (Mondal et al., 2008) with some alteration. To prevent aggregation, the internal phase, acetone from the nano-dispersion was evaporated with slow stirring at room temperature instead of quick rotative evaporation under partial vacuum.

Characterization of nanoparticles: LICOMP particle size analyze was used for measurement of size and zeta potential of the nanoparticles developed. The surface morphology (roundnesss, smoothness and formation of aggregates) was studied by Atomic force microscopy and Scanning electron microscope.

Loading efficiency of drug: The loading efficiency of LTZ was calculated by Spectrophotometry (Libra S32 PC) at $213 \mathrm{~nm}$ against standard LTZ sample and PLGA nanoparticle.

Preparation of diet: The diet used in present study was commercially available and hatchling (fry) feed (first bite) was procured from Hikari, Japan. About $100 \mathrm{~g}$ of feed was weighed and used for incorporation of PLGA conjugated Letrozole.

Incorporation of LTZ-loaded PLGA NPs into fish feed: PLGA NPs conjugated LTZ were incorporated into the feed as follows: The appropriate amount of LTZ -loaded PLGA NPs i.e. 5, 25, 50, $100 \mathrm{mg}$ (weighed accurately using an electrical balance) was dissolved in $50 \mathrm{ml}$ of $95 \%$ acetone. The required quantity of powdered feed was taken in an enamel tray and the LTZ-loaded PLGA NPs dissolved in acetone were sprayed uniformly using a chromatogram column sprayer.

Preparation of negative control: The negative control diet was prepared in the same manner using only the solvent (acetone).

Preparation of positive control: The positive control diet was prepared in the same manner using only $100 \mathrm{mg}$ pure Letrozole in the solvent (acetone).

Incorporation of PLGA NPs into fish feed: PLGA nanoparticles incorporation into the diet was accomplished as follows: The appropriate amount of PLGA nanoparticles that is $20 \mathrm{mg}$ (weighed accurately using an electrical balance) was dissolved in $50 \mathrm{ml}$ of $95 \%$ acetone. The required quantity of powdered feed was taken in an enamel tray and the PLGA nanoparticles dissolved acetone was sprayed uniformly using a chromatogram column sprayer.

Development of brood-stock: The brooders were reared in cemented tank $(6 \times 4 \times 3 \mathrm{ft})$ until they are matured. The gravid female and male swordtail (identified based on their external characteristics) were released in aquaria $(2 \times 1 \times 1 \mathrm{ft})$ in the ratio of $2: 1(\mathrm{~F}: \mathrm{M})$. The fish were fed twice daily on artificial diet as well as mosquito larvae, tubifex, bloodworm, earth worm and zooplankton at libido.

Seed production of guppy: The female and male brooders were placed in a breeding trap to provide easy passage for the newly released young one. In about two weeks of their holdings, the parturition took place. The resultant fry (released in batches) were used for experimentation. The aquaria were aerated using an air blower.

LTZ-loaded PLGA NPs administration to fry:

Trial 1: This trial was conducted for 10 days. The two-day-old fry (intial weight $6.13 \mathrm{mg}$ ) were divided into 7 groups of 35 each and designated as $T_{1}, T_{2}, T_{3}$, $\mathrm{T}_{4}, \mathrm{~T}_{5}, \mathrm{~T}_{6}$ and $\mathrm{T}_{7}$ for negative control, positive control, PLGA nanoparticle $(20 \mathrm{ppm})$ and $5,25,50$ and $100 \mathrm{ppm}$ of LTZ-loaded PLGA NPs respectively. Fishes were fed daily (100\% body weight) for the first ten days.

Trial 2: This trial was conducted for 15 days. The one-day-old fry (initial weight $3.98 \mathrm{mg}$ ) were divided into 7 groups of 30 each and designated as $T_{1}, T_{2}, T_{3}$, $\mathrm{T}_{4}, \mathrm{~T}_{5}, \mathrm{~T}_{6}$ and $\mathrm{T}_{7}$ for negative control, positive control, PLGA nanoparticle $(20 \mathrm{ppm})$ and $5,25,50$ and 100ppm of LTZ-loaded PLGA NPs respectively. They 
were fed daily@100\% body weight for the first ten day and $75 \%$ for the next 5 days $\left(11^{\text {th }}\right.$ and $15^{\text {th }}$ day $)$.

Trial 3: This trial was conducted for 30 days. The two -day-old fry (initial weight $4.0 \mathrm{mg}$ ) were divided into 7 groups of 45 each and designated as $\mathrm{T}_{1}, \mathrm{~T}_{2}, \mathrm{~T}_{3}, \mathrm{~T}_{4}, \mathrm{~T}_{5}$, $\mathrm{T}_{6}$ and $\mathrm{T}_{7}$ for negative control, positive control (100ppm pure letrozole without nanoparticles), PLGA nanoparticle $(20 \mathrm{ppm})$ and 5, 25, 50 and 100ppm of LTZ-loaded PLGA NPs respectively. They were provided feed daily@100\% body weight for the first ten days, $75 \%$ for the next 15 days and $50 \%$ for the last 5 days.

Evaluation of all treatments: On termination of the experiments, all the surviving fish were harvested, counted and measured for weight and length and sexed by macroscopic inspection. The phenotypic sex of the treated and control fish was determined with the help of secondary sexual characters, such as the shape of the belly, presence of gonopodium, size of gonopodium, and modification of anal fin.

Gonopodial and gonosomatic index study: The standard length and the length of the gonopodium were measured for each fish. The gonopodial index (GPI) was calculated in terms of the gonopodial length as a percentage of the total body length. Then the whole body weight and the testes wet weight were measured for each fish.

The gonosomatic index (GSI) was calculated in terms of the gonadal weight as a percentage of the whole body weight.

The gonosomatic index (G.S.I.) for treated and control guppy was determined using the formula:

$$
\text { GSI }=\frac{\text { Total weight of gonad }}{\text { Total weight of fish }} \times 100
$$

Statistical analysis: Data on percentage of male produced in each treatment was analyzed using one way ANOVA to test the significant difference of mean values and standard error using SPSS 18 software.

\section{RESULTS}

Physiochemical characterization of PLGA and LTZ -loaded PLGA NPs: The particle size of the PLGA nanoparticles was found to be in the range of $18 \pm 63.8$ $\mathrm{nm}$ to $568 \pm 63.8 \mathrm{~nm}$ with an average size of $132.8 \pm 64.8$ $\mathrm{nm}$ and the PLGA-loaded letrozole nanoparticles (LTZ -PLGA NPs) were found to be in the range of $78 \pm 38.5$ $\mathrm{nm}$ to $487 \pm 73.8 \mathrm{~nm}$ with an average size of $216.7 \pm 73.5$ $\mathrm{nm}$ (Table 1).

Loading efficiency of LTZ with PLGA nanoparticles: The loading efficiency of LTZ calculated by Spectrophotometry (Libra S32 PC) measurement at wavelength (200 nm) against standard LTZ sample and PLGA nanoparticle was $48.57 \pm 6.84 \%$.

Male and female percentage and survival rate: The male percentage was $89.63 \pm 0.93$ for $\mathrm{T} 7$ at 10 days, $92.64 \pm 1.63 \%$ for $\mathrm{T} 7$ at 15 days and $100 \%$ for both T6 (50ppm) and T7 (100 ppm) at 30 days, lowest male percentage was found at T4 treatment of all groups. It was reported that the male percentage of treatment $\mathrm{T} 2$ (naked letrozole at $50 \mathrm{ppm}$ ) and treatment $\mathrm{T} 4$ (LTZ- PLGA NPs at $5 \mathrm{ppm}$ ) were $83.69 \pm 0.94 \%$ and $82.63 \pm 1.74 \%$ respectively for 30 days treatment. These finding shows that LTZ in nano forms can reduce about $90 \%$ of prescribed dose of letrozole for masculinization of ornamental fishes.

It was observed that the percentage of male production in treatment T4 during 10 and 30 days' time interval was increased from $56.63 \pm 0.84$ to $82.63 \pm 1.74 \%$. It is 'therefore' administrated LTZ- PLGA NPs at low dose ( $5 \mathrm{ppm}$ per $\mathrm{kg}$ ) for prolong period, presented significant sex reversal and also helped to reduce cost of drug and its adverse impact on experimental fishes. The sex ratio was significantly $(\mathrm{P}<0.001)$ altered in the LTZ-PLGA NPs treated groups in compare to control groups in all treatments with respect to trials and doses except T3 which has PLGA nanoparticle without letrozole (drug) and check the impact of nanoparticle on experimental fishes (Table 2).

Gonopodial index (GPI): There was a significant difference in the GPI between the control group and treated groups except PLGA nanoparticles fed groups. It was reported that gonopodium development was stimulated significantly $(\mathrm{P}<0.001)$ in all the LTZ -loaded PLGA NPs treated groups in compare to control and T3 as indicated by higher gonopodial index values. GPI was significantly increased from T4 to T7 (Table 3).

Gonadosomatic index (GSI): It was observed that, increase in the dose of LTZ PLGA NPs, there was a slight decrease in the gonadosomatic index of LTZ PLGA NPs treated groups females, whereas in treated males an increase in the dose showed an increase of gonadosomatic index. It is evident that ovarian development was suppressed significantly $(\mathrm{P}<0.001)$ in all the LTZ -loaded

Table 1. Particle size, zeta-potential and poly dispersive index of PLGA and LTZ-loaded PLGA NPs.

\begin{tabular}{lccc}
\hline Nanoparticles & Particle size (nm) & Zeta potential & $\begin{array}{c}\text { Poly dispersive index / normal } \\
\text { Standard Deviation }\end{array}$ \\
\hline PLGA & $132.8 \pm 64.8$ & $18.53 \mathrm{mV}$ & 0.534 \\
LTZ- PLGA & $216.7 \pm 73.5$ & $22.36 \mathrm{mV}$ & 0.354 \\
\hline
\end{tabular}

Mean \pm SD of 3 replicates sampled nanoparticles 
PLGA NPs treated groups, compared to control and $T_{3}$ group as indicated by higher GSI values (Table 4 ). The testicular development was stimulated considerably in the $T_{2}$, $\mathrm{T}_{4}, \mathrm{~T}_{5}, \mathrm{~T}_{6}$ and $\mathrm{T}_{7}$ treated groups. The gonadal development (both testicular and ovarian) was normal in control group $\left(\mathrm{T}_{1}\right)$ and PLGA nanoparticle $\left(\mathrm{T}_{2}\right)$ fed group (Table 4$)$.

\section{DISCUSSION}

The present work was undertaken to develop an efficient and effective delivery system by exploiting the emerging application of nanotechnology to administrate PLGA nanoencapsulated letrozole for altering the sex to be interested in ornamental fish. It is equally important that approach should be ecofriendly and economically viable, and also user friendly inducing agent for male production in fishes, since the nanoparticles can be absorbed through cell membrane therefore the effect on the target organ is more efficient.

Nano-encapsulation of letrozole with PLGA

Nanoparticle: LTZ-loaded PLGA nanoparticles was developed size ranging from $78 \pm 38.5 \mathrm{~nm}$ to $487 \pm 73.8$ $\mathrm{nm}$ with an average size of $216.7 \pm 73.5 \mathrm{~nm}$ and having loading capacity of $48.57 \pm 6.84 \%$ with average zeta potential of $22.36 \mathrm{mV}$. This is the first novel report of developing nanoparticles for fish sex reversal using aromatase inhibitor. However in bio-medical science various nanoparticles like Letrozole (LTZ) incorporated PLGA nanoparticles have been used to treat cancer (Mondal, et al.,2010).

LTZ-loaded PLGA NPs were prepared by solvent displacement technique. This yielded spherical powder particles with diameter of LTZ-loaded PLGA nanoparticles $15-100 \mathrm{~nm}$ and poly dispersity index of $0.087 \pm 0.019$. The loading efficiency as well as drug entrapment efficiency of LTZ-loaded PLGA NPs was $77.44 \pm 0.24$ and $43.03 \pm 2.20 \%$, respectively. The zeta potential values of LTZ-loaded PLGA NPs were found to be negative, -12 to $-19.50 \mathrm{mV}$ (Mondal et al., 2010).

The dexamethezone in PLGA nanoparticles was developed for treating disease like rheumatoid, (Park et al., 2012).The average size was $50 \mathrm{~nm}$ with drug loading efficiency was $56.18 \pm 5.39 \%$.

This is justified that the developed nanoparticle size occurred in between the reported nanoparticles size and particles are morphologically spherical and compact and shown more stable.

Masculinization using LTZ-loaded PLGA nanoparticles: In the present study, LTZ-loaded PLGA nanoparticles were administrated at 5, 25, 50 and 100ppm through diet for 3-day-old fry (after yolk sac absorption) for 10,15 and 30 days; lead to increase masculinization with increased concentration of letrozole loaded PLGA nanoparticles. Among LTZ-loaded PLGA nanoparticles treated groups, the lowest percentage of males (82.63\%) was observed in $5 \mathrm{ppm}$ group; while the highest percentage of males $(100 \%)$ was found at 50 and $100 \mathrm{ppm}$ when fed for 30 
Table 3. Gonopodial index (GPI) of males of all treated groups.

\begin{tabular}{cccc}
\hline Treatment & 10 days & 15 days & 30 days \\
\hline $\mathrm{T}_{1}$ & $23.35^{\mathrm{a}} \pm 0.64$ & $23.86^{\mathrm{a}} \pm 0.95$ & $23.85^{\mathrm{a}} \pm 1.83$ \\
$\mathrm{~T}_{2}$ & $26.64^{\mathrm{b}} \pm 0.46$ & $26.85^{\mathrm{c}} \pm 0.47$ & $26.48^{\mathrm{b}} \pm 1.56$ \\
$\mathrm{~T}_{3}$ & $23.96^{\mathrm{a}} \pm 0.69$ & $23.64^{\mathrm{a}} \pm 1.57$ & $23.69^{\mathrm{a}} \pm 1.04$ \\
$\mathrm{~T}_{4}$ & $23.59^{\mathrm{a}} \pm 1.39$ & $24.64^{\mathrm{b}} \pm 0.54$ & $26.48^{\mathrm{b}} \pm 0.57$ \\
$\mathrm{~T}_{5}$ & $28.35^{\mathrm{c}} \pm 1.07$ & $28.46^{\mathrm{d}} \pm 1.54$ & $29.69^{\mathrm{c}} \pm 1.98$ \\
$\mathrm{~T}_{6}$ & $29.46^{\mathrm{cd}} \pm 1.03$ & $30.68^{\mathrm{de}} \pm 1.05$ & $31.74^{\mathrm{de}_{1}} \pm 1.54$ \\
$\mathrm{~T}_{7}$ & $30.75^{\mathrm{d}} \pm 1.45$ & $31.46^{\mathrm{e}} \pm 1.35$ & $32.64^{\mathrm{e}} \pm 1.50$ \\
\hline $\mathrm{P}$ value & $<0.001$ & $<0.001$ & $<0.001$ \\
\hline
\end{tabular}

Mean \pm SD of 3 replicates sampled GPI of males of all treated groups

Table 4. Gonadosomatic index (GSI) of all treated groups.

\begin{tabular}{|c|c|c|c|c|c|c|}
\hline \multirow{2}{*}{$\begin{array}{l}\text { Treat- } \\
\text { ment }\end{array}$} & \multicolumn{2}{|c|}{10 Days } & \multicolumn{2}{|c|}{15 Days } & \multicolumn{2}{|c|}{30 Days } \\
\hline & Male & Female & Male & Female & Male & Female \\
\hline $\mathrm{T}_{1}$ & $2.23^{\mathrm{a}} \pm 1.44$ & $18.47^{\mathrm{f}} \pm 0.65$ & $2.20^{\mathrm{a}} \pm 1.43$ & $18.42^{\mathrm{f}} \pm 1.42$ & $2.75^{\mathrm{a}} \pm 0.35$ & $18.54^{\mathrm{f}} \pm 1.07$ \\
\hline $\mathrm{T}_{2}$ & $5.73^{\mathrm{e}} \pm 0.86$ & $14.65^{\mathrm{e}} \pm 0.53$ & $5.21^{\mathrm{c}} \pm 1.42$ & $14.85^{\mathrm{e}} \pm 1.42$ & $5.74^{\mathrm{d}} \pm 1.08$ & $14.54^{\mathrm{e}} \pm 0.42$ \\
\hline $\mathrm{T}_{3}$ & $2.75^{\mathrm{a}} \pm 1.07$ & $18.23^{\mathrm{f}} \pm 0.64$ & $2.29^{\mathrm{a}} \pm 1.54$ & $18.24^{\mathrm{f}} \pm 1.34$ & $2.63^{\mathrm{a}} \pm 0.85$ & $18.56^{\mathrm{f}} \pm 1.65$ \\
\hline $\mathrm{T}_{4}$ & $3.65^{\mathrm{b}} \pm 0.78$ & $3.64^{\mathrm{d}} \pm 0.65$ & $3.67^{\mathrm{b}} \pm 0.54$ & $13.36^{\mathrm{d}} \pm 0.75$ & $3.64^{\mathrm{b}} \pm 1.62$ & $13.56^{\mathrm{d}} \pm 0.57$ \\
\hline $\mathrm{T}_{5}$ & $3.75^{\mathrm{c}} \pm 1.96$ & $12.54^{\mathrm{c}} \pm 1.64$ & $3.87^{\mathrm{b}} \pm .1 .45$ & $11.67^{\mathrm{c}} \pm 1.57$ & $4.66^{\mathrm{c}} \pm 0.53$ & $11.57^{\mathrm{c}} \pm 1.56$ \\
\hline $\mathrm{T}_{6}$ & $4.75^{\mathrm{d}} \pm 0.56$ & $11.24^{\mathrm{b}} \pm 1.43$ & $4.90^{\mathrm{c}} \pm 0.46$ & $10.64^{\mathrm{b}} \pm 1.42$ & $5.01^{\mathrm{d}} \pm 1.36$ & $10.75^{\mathrm{b}} \pm 0.86$ \\
\hline $\mathrm{T}_{7}$ & $5.95^{\mathrm{f}} \pm 1.86$ & $10.02^{\mathrm{a}} \pm 1.54$ & $6.01^{\mathrm{d}} \pm 0.53$ & $9.68^{\mathrm{a}} \pm 0.35$ & $6.32^{\mathrm{e}} \pm 0.15$ & $9.54^{\mathrm{a}} \pm 1.54$ \\
\hline$P$ value & $<0.001$ & $<0.001$ & $<0.001$ & $<0.001$ & $<0.001$ & $<0.001$ \\
\hline
\end{tabular}

Mean $\pm \mathrm{SD}$ of 3 replicates sampled GSI of males and females of all treated groups

days.Das (2007) observed that the manipulation of the sex ratio in Oreochromis mossambicuswas possible by oral administration of letrozole (a non-steroidal aromatase inhibitor). Dietary administration of letrozole (100 and $200 \mathrm{ppm}$ ) was produced $92-100 \%$ males when fed to 5-6 day-old-fry for 30 days.

Fadrozole was used to masculinization in several species like Oncorhynchus tshawytscha (Piferrer et al., 1994), Epinephelus merra (Nakamura et al., 1998) ,O. kisutch (Hong and Donaldson, 1998), Oreochromis niloticus (Kwon et al., 2000), Acanthopagrus schlegeli (Lee et al., 2001), Cyprinus carpio (Tzchori et al., 2004), and Siganus guttatus (Komatsu et al., 2006).

A series of experiments were carried out by Kwon et al. (2000) in which genetically female Nile tilapia Oreochromis niloticus fry were treated with fadrozole, a nonsteroidal aromatase inhibitor, during the period of liable phase. Group of tilapia fry medicated with AI during the first 30 days following yolk sac reabsorption (7-37 days dph) showed a dose dependent increase in the percentage of males. The percentage of males remained approximately constant $(92.5-96.0 \%)$ from
200-500 mg/kg (Kwon et al., 2000).

In the present study, a series of experiments were carried out to induce masculinization using LTZloaded PLGA nanoparticles during the sex differentiation period. Guppy Poecilia reticulata fry were treated with LTZ-loaded PLGA nanoparticles at dosages 5, 25, 50 and 100 ppm diet for 10, 15 and 30 days. The results showed an increase in the proportion of males with dosage and duration of treatment and all reported works supported the present work.

Gonopodium index (GPI): In the present research the gonopodium index (GPI) of LTZ-loaded PLGA nanoparticles treated groups (males) showed a slight increase with an increase in the dosage. The treated groups $\left(T_{3}, T_{4}, T_{5}, T_{6}\right.$ and $\left.T_{7}\right)$ are significantly differ $(\mathrm{P}<0.001)$ from control group $\left(\mathrm{T}_{1}\right)$ and PLGA nanoparticle treated group $\left(\mathrm{T}_{3}\right)$.

Gonopodium lengths were unaffected by estradiol benzoate and DDT congeners. However, Bayley et al. (2002) showed that juvenile male guppies had smaller gonopodium after exposure to vinclozolin, $p, p$-DDE and flutamide. This may be from age-relation. The 
gonopodium length was significantly correlated with female orientation response to the male (Bayley et al., 2002). Exposure to LTZ-loaded PLGA nanoparticle congeners possibly affects this male sexual character since gonopodial development in poeciliids is non-steroid dependent.

Gonadosomatic index (GSI): In the present study the gonadosomatic index of LTZ-loaded PLGA nanoparticles treated groups (females) showed a slight decrease with an increase in the dosage. However, the GSI of males increased with an increase in the dosage of LTZ -loaded PLGA nanoparticles(Table no.4). Das (2007) administered different doses of letrozole alone or in combination with $17 \alpha$-MT and observed that there was no major effect of letrozole and $17 \alpha$-MT on GSI of $O$. mossambicus. The present GIS results of the study confirm with those of Piferrer et al. (1994) who reported that fadrozole treated genetic females had developed into phenotypic males which were indistinguishable from regular males in terms of GSI and rate of maturity. Ankley et al. (2002) also reported similar observations that the GSI of males increased with an increase in the dosage of fadrazole which was similar with present study results that the GSI of males increased with an increase in the dosage of LTZ -loaded PLGA nanoparticles.

\section{Conclusion}

The present study developed a new Letrozole (LTZ) -loaded PLGA nanoparticles for effective delivery of the masculinization drug. The gonopodium index and GSI showed increasing order in male and female respectively with dose of LTZ-loaded nanoparticles. The use of nanoparticles significantly showed the effect on masculinization as compared with naked drug delivery.

\section{REFERENCES}

Ankely, G.T., Kahl, M.D., Jensen, K.M., Hornung, M.W., Korte, J.J., Makynen, E.A. and Leino, R.L. (2002). Evaluation of the aromatase inhibitor fadrozole in a short term reproduction assay with the fathead minnow. Toxicol. Sci. 67: 121-130.

Bayley, M., Junge, M. and Baatrup, E. (2002). Exposure of juvenile guppies to three antiandrogens causes demasculinization and a reduced sperm count in adult males. Aquatic Toxicology., 56: 227-239.

Brigger, I., Dubernet, C. and Couvreur, P. (2002). Nanoparticles in cancer therapy and diagnosis. Advanced Drug Delivery Reviews. 54: 631-651.

Brodie, A. (1991). Aromatase and its inhibitors an overview. J. Steriod Biochem. Mol. Biol. 40:255-261.

Das, R. (2007). Effect of aromatase inhibitor on gonadal development in Oreochromis mossambicus (Peters). M.F.Sc. Thesis, KVAFSU. Bidar. pp57.

Hallgren, S.L., Linderoth, M. and Olsen, K.H. (2006).
Inhibition of cytochrome $\mathrm{p} 450$ brain aromatase reduces two male specific sexual behaviours in the male Endler guppy (Poecilia reticulata). Gen. Comp. Endocrinol. 147: 323-328.

Hong, W. and Donaldson, E.M. (1998). Effects of the aromatase inhibitor fadrozole on gonodal development in coho salmon (Oncorhynchus kisutch). Asian Fish Sci. 10:339 -345 .

Hughes, G.A. (2005). Nanostructure mediated drug delivery. Nanomedicine. 1: 22-30.

Komatsu, T., Nakamura, S. and Nakamura, M. (2006). Masculinization of female golden rabbitfish Siganus guttatus using an aromatase inhibitor treatment during sex differentiation. Comp. Biochem. Physiol. C. Toxicol. Pharmacol. 143: 402-409.

Kwon, J.Y., Haghpanah, V., Kogson-Hurtado, L.M., Mcandrew, B.J. and Penman, D.J. (2000). Masculinization of genetic female Nile tilapia (Oreochromis niloticus) by dietary administration of an aromatase inhibitor during sexual differentiation. J. Exp. Zool. 287: 46-53.

Lee, Y.H., DU, J.L., Yen, F.P., Lee, C.Y., Dufour, S., Huang, J.D., Sun, L.T. and Chang, C.F. (2001). Regulation of plasma gonadotropin II secretion by sex steroids, aromatase inhibitors, and antiestrogens in the protandrous black porgy, Acanthopagrus schlegeli Bleeker. Comp. Biochem. Physiol. B 129:399-406.

Mondal, N., Halder, K.K., Kamila, M.M., Debnath, M.C., Pala, T.K., Ghosal, S.K., Sarkar, B.R. and Ganguly, S. (2010). Preparation, characterization, and biodistribution of letrozole loaded PLGA nanoparticles in Ehrlich Ascites tumor bearing mice. International Journal of Pharmaceutics. 397: 194-200.

Mondal, N., PAL, T.K. and Ghosal S.K. (2008). Development, physical characterization, micromeritics and in vitro release kinetics of letrozole loaded biodegradable nanoparticles. Pharmazie. 63: 361-365.

Nakamura, M., Dobayashi, T., Chang, X.T. and Nagahama, Y. (1998). Gonadal sex differentiation in teleost fish. $J$. Exp. Biol. 281:362-372.

Park, J.S., Yang, H.N., Jeon, S.Y., Woo, D.J., Kim, M.S. and Park, K.H. (2012). The use of anti-COX2 siRNA coated onto PLGA nanoparticles loadingdexamethasone in the treatment of rheumatoid arthritis. Biomaterials. 33: 8600-8612.

Pasmanik, M. and Callard, G.V. (1988). Changes in brain aromatase and 5-reductase activities significantly with seasonal reproductive cycle in gold fish (Carassius auratus). Endocrinol. 122: 1349-1356.

Piferrer, F., Zanuy, S., Carrillo, M., Solar, I.I., Devlin, R.H. and Donaldson, F.M. (1994) Brief treatment with an aromatase inhibitor during sex differentiation causes chromosomally female salmon to develop as normal, functional males.. J.Exp.Zool. 270:255-262.

Tzchori, I., Zak, T. and Saches, O. (2004). Masculinization of genetic females of the common carp (Cyprinus carpio L.) by dietary administration of an aromatase inhibitor. The.Isr J.Aqu., 56(4): 239-246.

Vauthier, C., Dubernet, C., Chauvierre, C., Brigger, I. and Couvreur, P. (2003). Drug deliveryto resistant tumors: the potential of poly (alkyl cyanoacrylate) nanoparticles. J. Control. Release. 93: 151-160. 